Mote: «Se a mulher se revolta contra o homem, nada fica intacto»

\title{
Desmontar a ordem, abrir as parábolas: A lei do género e o género fora da lei
}

\section{Emerson Inácio}

Universidade de São Paulo (USP)

Quando o burguês se revolta contra o rei, ou quando o colono se revolta contra o império, é apenas um chefe ou um governo que eles atacam, tudo o resto fica intacto, os seus negócios, as suas propriedades, as suas famílias, os seus lugares entre amigos e conhecidos, os seus prazeres. Se a mulher se revolta contra o homem nada fica intacto; para a mulher, $o$ chefe, a política, o negócio, a propriedade, o lugar, o prazer (bem viciado), só existem através do homem.

"Extractos do diário de D. Maria Ana, descendente directa de D. Mariana sobrinha de D. Mariana Alcoforado, e nascida por volta de 1800", Novas cartas Portuguesas 
Na novela A confissão de Lúcio, de Mário de Sá-Carneiro, um fato vivido pelo protagonista, em sua estada em Paris, salta aos olhos dos leitores: a festa a que ele fora em casa da bailarina fulva, evento iluminado por uma reveladora luz elétrica, que causa ao narrador, Lúcio, certo torpor. Sobretudo porque aquela iridescência lhe proporcionara uma visão abrangentemente clara dos corpos dos dançarinos ali atuantes, seminus e semivestidos, lascivos e perversos. Ao lado disso, dois contrapontos: o corpo fluido e obnubilado de Marta, que, sendo talvez Ricardo, nunca se expunha para além da neblina e da escuridão da casa em que às vezes recebia o protagonista-narrador. Noutro ponto, o corpo rígido e tenso de Lúcio, vestido e sitiado, como que submetido a um regime maior que lhe impuseram antes mesmo que ele existisse (Sá-Carneiro 1989).

Nessa pequena digressão, à guisa de introito, podemos inferir sobre qual papel o corpo - aqui percebido não apenas no seu aspecto discursivo-literário, mas também físico, escatológico e sentinte - talvez tenha ocupado no espaço literário e estético português durante boa parte do século XX. 0 modernismo órfico, na sua demanda de desobstrução de mentalidades e de sintonia da arte portuguesa às linhas mais vanguardistas européias, não conseguira de maneira eficaz pôr em tela um corpo que não fosse ou excessivamente sem órgãos e vazio, como aquele percebido na poesia de Pessoa, ou mesmo excessivamente mental e frustrado, como o vemos na poesia de Sá-Carneiro. O corpo outro, então, uma blague: Violante de Cysneiros, somente assinatura no fim de um poema, não passara de uma enorme brincadeira dos que conceberam a revista Orpheu, que não chegava nem ao ato performativo próprio do poema.

Os comentários aqui aduzidos, tanto o literário quanto o paraliterário, podem parecer pouco conectados à matéria que aqui discutimos. Seriam, não fosse um sinal do quanto ainda era problemático o trato estético do corpo no âmbito da cultura portuguesa, mesmo se considerando que já fora visto como forma de obtenção e exploração do capital, em Marx; potencializado na sua importância como lugar do sujeito em Nietzsche e problematizado na sua relação com o sentimento, o pensar e dor, em Freud. Na tradição literária portuguesa do século XX, ainda, uma eterna visitação ao corpo escatológico de Inês de Castro, que mesmo 'sendo', sem nunca ter sido, depois de morta, rainha, tivera seu corpo 
de mulher dilacerado pelas intrigas políticas de outro Portugal, com medos a perder-se para a Espanha. A Inês, desprovida de vivência e que não tinha mais carnes e nem corpo que as suportasse, reaparece rediviva numa tradição que oblitera o corpo como fonte do saber, do poder e dos discursos e que só pode ser depois de morta.

Mas o que nos interessa aqui é tentar compreender como, à esteira dessa tradição, efetivamente se inserem nesse arranjo os outros corpos, não os silenciados no Modernismo ou submetidos às imbricadas relações entre poderes e saberes. Mas aqueles que, destoando de seu também tradicional apagamento, tenderão a promover a transgressão e a erupção, seja da forma como a cultura os vê, seja na forma como atuam na transformação dos diversos olhares que sobre o corpo recaem, seja no concerto literário, seja na cultura ou na política.

Um discurso literário que desconstrói princípios cristalizados dentro da perversa lógica cultural e ideológica caberá no interior dos previsíveis modelos de entendimento da matéria literária, como o são os gêneros e na forma como ainda os entendemos? Em se tratando do fenômeno materializado nas Novas Cartas Portuguesas, podemos adiantar a resposta e a conclusão dessa fala: não, não podemos! E por quê? Porque se pensamos que toda a lógica cultural do ocidente, sobretudo da Europa fora formada a partir de uma experiência masculina de mundo, talvez os gêneros literários também estejam eles plasmados dessa experiência que compartimentaliza, exclui e oblitera a diferença e a diversidade. Pensando com Ria Lamaire (1994: 58-71), é preciso desmontar toda uma lógica discursiva e cultural talhada no homem e no masculinos como centros e destinos dos saberes, para em seu lugar não necessariamente criar um mundo aos moldes das experiências femininas, mas suficientemente abrangente a ponto de, por exemplo, a linguagem não ser um exemplo do que não é ser mulher.

A citação-epígrafe sempre me pareceu, na economia de Novas Cartas Portuguesas, um tanto enigmática: primeiro por que parece relacionar elementos aparentemente díspares - burguês/rei, colono/império, chefes, negócios, posses, prazeres, instituições instâncias que numa primeira visada parecem não conformar um todo orgânico ou um conjunto capaz de ser um exemplo contrário à insubmissão da mulher. Construção abissal, 
mise-en-abyme ou discurso aparentemente circunscrito, mas potente e multidirecionado e mesmo multidirecionável? Diante de tanto, proponho que haja em Fluxo-Floema e Novas Cartas Portuguesas um processo de ruptura com as formas tradicionais do gênero literário em favor de um texto emancipatório, intertextual, transtextual e sempre iruptivo, e que tal ruptura só seja mesmo possível por que se trata de um texto escrito por mulheres.

Os elementos deste mote, se vistos na sua representação ideológica, e ainda mesmo como articulação discursiva, me levam a inferir de que se tratam de formas de o Poder (com "P" maiúsculo, P de pau, pila, paradigma, de pauta, de padrão) se fazer representar nos diversos âmbitos da vida e que, sobretudo, são poderes que recaem ainda com mais força sobre o estatuto de gênero ocupado pela mulher. 0 poder, como bem nos lembra Michel Foucault, em Vigiar e Punir, é eficiente por que opera não apenas nas panópticas instituições sociais como a cela, a clausura, a prisão, a escola, mas, de maneira silenciosa sobre o corpo daqueles e ainda mais daquelas que devem, por força de lei, submeterem-se sem questionamentos a este poder (Foucault 2002: 162-187).

Posteriormente, em entrevista concedida à revista Quel Corps, em 1975, o filósofo relembra que o corpo do rei materializa uma lógica de poder e a própria monarquia e a força do estado que representa e, de maneira correlata, poderíamos estender esta sistemática ao império e às formas de opressão por ele exercidas sobre os seus colonos (Foucault 1979: 145-152). No fim, são corpos masculinos que dominam outros corpos masculinos e todos dominam os corpos abjetos - seja do escravo, do servo, da mulher - mas sem que a idéia de masculinidade e poder, instâncias que historicamente se confundiram com o próprio homem como manifestação de um gênero sexual, em nenhum momento seja posta em prova. Ao revoltar-se contra um poder superior a si mesmo e capitular ou ser submetido por este mesmo poder só prova para o homem a sua capacidade de defender as instituições e valores que lidera e domina, seus princípios morais e sua honra, demonstrando no fim que a resistência ou recusa de uma lei, seja ela qual for, só revela a manutenção desta mesma lei, apenas que executada de outra forma.

Um dialogo silencioso se estabelece entre Fluxo-Floema e Novas Cartas Portuguesas; nesse caso: na "textualidade" de Hilda Hilst em cinco das cinco narrativas temos os 
personagens se rebelando contra as formas de poder ou a elas se relacionando diretamente: seja na lei particular do desejo assassino, da parafilia manifesta em "Osmo", em que domínio e prazer se confundem na mão que "escreve" e estrangula; seja no aparecimento de uma alteridade demoníaca além-Gênero e pós-Deus, em "Lázaro", mas que conforma o projeto divino de ressuscitar o judeu morto em nome de um poder divino maior. Ainda em "Fluxo" e "Floema", no embate entre narradores/enunciadores e as formas de expressão que se escasseiam diante do potencial transgressivo do texto: há um corpo textual e um corpo no texto que precisam ser respeitados enquanto forma de poder e lei; há uma instância enunciativa que demanda um dizer (fascista?) masculino, que diminui e arrefece artista, anão, Porco e Unicórnio e os submete a um rumor que não há de deixar intacto quem contra este rigor se rebela, reconduzindo a um estágio imaterial cuja existência só se legitima na linguagem deficiente (Hilst 2003: 211).

Esta "legitimação" - recomposição do aspecto "legal”, legítimo do discurso, obriga a dizer, impõem-se em forma e na regularidade do fluxo de conteúdo. Entretanto, como fica claro desde a primeira teia enunciativa de Fluxo-Floema, é preciso adentrar um texto-poço escrito numa língua de ressonâncias e que, para tanto, transgride, recuperando o aspecto perdido de uma Literatura que não mais se rebela. As imagens recorrentes no livro como o poço, a caverna, o corpo, a carne, a cela, o cercado, o texto, assumem, nesse sentido, um duplo movimento: se balizam e limitam o campo discursivo, por outro são espaços que se esboroam, se expandem para além do próprio limite, como se enunciado e enunciadores estabelecessem um pacto em que os espaços de fora limitam enquanto que o interior significaria as múltiplas possibilidades de deriva, de desfazimento, de descosura ou de "desclausura", para lançar mão aqui de um vocabulário próprio de Novas Cartas Portuguesas, entendendo as textualidades aqui lidas a partir de sua própria gramática.

Nestes espaços, o corpo, escrito, grafado, marcado pela morte, pelo prazer, pelo desejo, pela perversão revoluciona o texto e nele se inscreve, em busca da corpografia, a que indiretamente já aduzimos aqui, compreendendo-a como grafia do corpo nas instâncias variadas que sustentam as textualidades literárias aqui vivenciadas. Coincidentemente, as figuras/ os personagens/ os enunciadores/ os narradores/ os eus-textuais sucumbem 
diante de certas impossibilidades, dentre as quais uma força maior que lhes obriga e impõe, não deixando réstia de dúvida sobre o fato de que seja a transgressão do unicórnio que escreve com o chifre, seja na tentativa de empreender uma Trindade-Escrita, nada ficará intacto, tendo tudo sido ao fim submetido ao imperativo da ordem masculina que atravessa Gênero Sexual, gênero literário: "de lésbicas nos chamarão" (Barreno/Horta/Costa 2010: 77) e "o[s] senhor[es] esta[rão] me pondo na bunda, compreende[m]? "(Hilst 2003: 214215).

Tudo fica intacto no caso de Osmo (idem: 73-105); Chamilly, Noel e do Pai Estuprador (Barreno/Horta/Costa 2010). A título de exemplo histórico-literário, o mítico personagem Ngungunhane, ficcionalizado por Ungulani Ba Ka Khosa, em Ualalapi, obra moçambicana publicada em 1987, parece representar bem aquilo que a Arte e a História também refletem: depois de sua captura por Mouzinho de Alburquerque, em fins de 1895, será exibido pela administração colonial nas ruas de Chaimite e Lisboa. 0 Leão de Gaza, notabilizado tanto por sua capacidade guerreira quanto por ser um estratéga ímpar, será diminuído em suas capacidades de homem, tratado como animal, para no fim ser desterrado nos Açores. Notemos um detalhe desta breve história: contrariamente ao que ocorria, Ngungunhane não será morto, mas desterrado em Angra do Heroísmo.

Piedade? Nenhuma, já que se tratava de deixar claro para o Ex-Imperador de Gaza e, sobretudo, para o seu revoltoso povo o tamanho do poder colonial sobre seu corpo, sua vida e mesmo sobre a sua revolta. Neste caso, ao capturá-lo Mouzinho de Albuquerque reitera o princípio da masculinidade portuguesa muito bem expresso na primeira instância do canto I de Os Lusíadas - "As armas e os barões assinalados" -, reiterados na crueza de Pedro I, na antevisão de um Dom Manuel, na ação do Gama e celebrada em corpo e férreo cano erguido na ilha do Amores e na conquista amorosa de Lionardo, que submete a ninfa ao seu desejo, enfim. Poupar a vida de Ngungunhane é, antes de mais, submetê-lo, para que "todo o resto fique intacto" e se mantenha o poder nas mãos de e pelos homens, já que uma das concessões ao líder africano será o de seguir para o desterro com parte entourage, ou seja, "família", "amigos", "prazeres”.

Revolta possível apenas pelo corpo liberto na escrita: “o que podem as palavras" 
(Barreno/Horta/Costa 2010: 220), afinal? “Oh! Oh! Tenho uma, uma idéia, uma excelente idéia: vou tentar formar palavras com este resto de verdura! (...) não vou escrever nenhum romance" (Hilst 2003: 216), responderá o Unicórnio, corpo só possível na linguagem.

Claro, ainda, nos parece, que, seja a revolta qual for ou contra quem for, se partida de um homem, acaba por representar uma enorme mudança cujo fim último não será, senão, manter o poder nas mãos de outros homens, seja na norma literária, seja na conformação de padrões capazes de produzir, por exemplo, adjetivações tais como "literatura de mulheres". Trata-se, pois, de um aparente câmbio, próprio das relações de rivalidade, potência, pilas milimetricamente medidas como prova de reconhecimento da supremacia do homem, ser do sexo masculino, sobre o outro, como já há algum tempo nos aludiu Ewe Sedwigck (1997) e Pierre Bordieu (1999), só para citar trabalhos fundadores sobre a questão do poder masculino.

Em última instância, o que se conjuga é a manutenção de uma lei feita por homens, num regime a eles devotado e cujos efeitos recaem sobre todos os que correm (e nem sempre) em paralelo ao poder por estes exercido: o burguês, o colono, os subordinados em geral. E esta lei nem foge ao campo cultural, tampouco ao espaço estético, mas mais ainda os absorve na criação de um regime de restrição que determina quem pode e deve produzir, por exemplo, literatura. Derrida, a respeito dessa lei implícita à prática literária, enfatizará que é necessário desnaturalizar o gênero literário e retirá-lo de um campo dicotômico profundamente ligado as lógicas excludentes da linguagem.

Fluxo-Floema e Novas Cartas Portuguesas representam literariamente textos que estabelecem uma ruptura com os "padrões" enunciativos vigentes nas Literaturas de Língua Portuguesa, seja pelo caráter transgressivo de sua forma, seja pelos temas que reclamam e discursivizam, já que não se tratam de "narrativas" constituídas a partir dos traços de força atinentes a este gênero e nem de poemas em prosa ou de prosa poética: mas de um texto escrito, grafado do corpo, no trânsito pelas várias formas assumidas pelo texto literário. Trata-se de recolocar o texto no campo de sua liberdade e não mais dentre de um protocolo, de uma lei que submete o conteúdo à forma. Para as três autoras, "escrever com dignidade”, como alude Hilda Hilst, outra que desafia e não passa incólume (Hilst 2003: 21), 
redunda do fato de que "não interessa o objecto, apenas pretexto, mas antes a paixão" e "antes o seu exercício" (Barreno/Horta/Costa 2010: 3). Ora, se a escrita digna se relaciona à paixão e ao prazer, estes são um exercício realizável na escrita, como vemos em Novas Cartas Portuguesas; é sempre válido a reiteração de que o par acima estejam intimamente ligados à experiência do corpo e com a criação de uma nova gramática capaz de dizer-lhe em termos ficcionais. Nesse sentido, esta nova gramática corpóreo-textual, escrita que é revoltosa, mas antes manifestação de dignidade, paixão e prazer, nasce, como dirá Derrida (1986), de um engendramento (ou "invaginação") só possível no corpo da mulher. E aqui, jogamos com a polissemia do par homônimo/homófono Gênero/gênero e com as possibilidades abertas pelo radical latino genus, atinente a ambos os termos: um corpo em constante transformação, que pode transmudar-se em outro e em novas identidades, sem que se comprometa, pode gerar textos que correspondam a cisão com a lei dos gêneros, sejam eles quais forem propondo certo resgate do potencial ilimitado da linguagem literária.

Observa-se em obras que tematizam as questões ligadas ao corpo, ao gênero e à diversidade sexual o contumaz uso de formas híbridas de expressão. Normalmente, tais textos lançam mão da tênue fronteira entre os gêneros literários para, a partir daí, constituírem um espaço possível para temas que por sua natureza transgressora não podem ser ditos dentro de padrões estanques. Tomemos como exemplo disso a produção poética de Al Berto e Luis Miguel Nava, em Portugal; ou de João Gilberto Noll, Clarice Lispector, Carolina Maria de Jesus e Adélia Prado, no Brasil. Nesta sequência de autores, o uso recorrente de uma forma que lembrar a prosa ou o poema ou que se auto-intitulam como tal, denotam a recorrência de maneira contumaz a outra forma literária.

Ainda que nos pareça dada como assentada em sua interatividade, a estrutura de gênero de forma alguma se livra de uma norma que a regulamente, já que se baseia num telos, que rejeita a impureza, a mistura, a anormalidade e a monstruosidade, baseando-se para tanto nas estruturas que sustentam o pensamento as relações sociais e culturais como um todo, boa parte delas baseada num modelo criado e difundido por homens que se rebelaram contra o cânone e as formas, para necessariamente constituírem na sequência 
como cânones e formas majoritárias. Em outras palavras, há uma lei dentro da própria lei do gênero, que lhe garante condições de separar, excluir, hierarquizar e normatizar, as formas artísticas quais forem, já que a lei demanda uma pureza identitária essencial. No caso das Novas Cartas Portuguesas, a afirmativa de Dona Maria Ana, epígrafe, parece antever a forma como esta textualidade será tratado por mais de 40 anos: a sua configuração apenas como manifesto feminista ou uma textualidade voltada à uma prática emancipatória que se distanciava da Literatura como expressão.

Nada, assim, fica intacto já que, o gesto neogramatical das autoras - a prática transgressiva representada por um texto que é um ser que é nada e que é tudo e que por isso se mitifica - implica necessariamente na transgressão de um ordenamento que é histórica e culturalmente identificado com o masculino enquanto gênero e com o homem enquanto produtor. A proposta de cisão revelada em Novas Cartas Portuguesas, neste sentido, "fere" a lógica dos gêneros literários, a lei do gênero como aponta Derrida, desestabilizando não apenas o sistema literário que a comporta, bem como sua própria estrutura como obra, uma vez que a condenação decorrente da rebeldia se dá no campo metonímico: Novas Cartas são retiradas do expressivo espaço de sua textualidade e é deslocada para o nível de seu continente, o livro; um texto de arte ideológica e intencionalmente construído, ousamos dizer, será decaído de sua monumentalidade e lançado apenas à cela fria do livro, destituído de paixão, de corpo, de orgasmo, prazeres e afetos que caracterizam intensamente a obra, como leremos pela mão de vários críticos, mesmo pela função unicamente política que lhes será atribuída ou, no fim, o obscurecimento da obra no concerto maior do cânone literário português. Com FluxoFloema não terá sido diferente, posto que, como ars poetica contruída a meio de caminho, enunciará a cartografia literária de Hilda Hilst: o investimento no lado incômodo, excessivo e inusitado da linguagem, mimetizando-se pornógrafa, erótica, odiosamente preterida dos arranjos epocais e geracionais, muito lida, pouco percebida.

Penso que se estas autoras se rebelam contra as formas criadas pelo homem, nada fique realmente intacto. Sobretudo por que ao criarem um novo regime sem regime, uma lei sem lei, uma forma-corpo-texto que genealogicamente engravida, pari, cria e lançarem no 
mundo obras sempre exponenciais, sempre em potência, saltam o cercado poetizado por Paula Tavares e passam a sugerir a liberdade como principio fundante: é imperativo ser mulher, fazer literatura e dar frutos! Mais que isso, escrever como mulher-pessoa, mulhersujeito-de-si.

"O que pode a literatura? Ou antes: o que podem as palavras" (Barreno/Horta/Costa 2010: 197), senão para “escrever as coisas de dentro (...) complicadíssimas" (Hilst 2003: 20) e, quem sabe, ensejar um outro começo onde nada mesmo fique intacto para o começo de um poema? E nesse recomeço, instaurar, fora da polis, o início da liberdade para o corpo da mulher e para a sua literatura.

\section{NOTA}

\footnotetext{
${ }^{1}$ Sem querer por em dúvida minha própria leitura, penso na minha condição e na capacidade que aqui tenho de também, como crítico, professor e homem, manifestar instâncias de poder que aqui questiono. É um risco que preferi assumir, inclusive, com o uso da 1a. pessoa do singular, a instância mais fraca do discurso, visto que pode se referir a todos e não ser, também e ao mesmo tempo, ninguém.
} 


\section{Bibliografia}

Barreno, Maria Isabel/Maria Teresa Horta/ Maria Velho da Costa (2010), Novas Cartas Portuguesas, Edição Anotada, Org. Ana Luísa Amaral, Lisboa, Dom Quixote.

Derrida, Jacques (1986), Parages, Paris, Galilée.

Foucault, Michel (1979), "Poder-Corpo", Microfísica do Poder, Trad. de Roberto, Machado, Rio de Janeiro, Graal, 145-152.

-- (1987), “O Panoptismo”, Vigiar e Punir, Trad. Raquel Ramalhete, Petrópolis, Vozes, 162187.

Hilst, Hilda (2003), Fluxo-Floema, São Paulo, Globo.

Sá-Carneiro, Mário de (1989), A Confissão de Lúcio, São Paulo, Princípio.

Lamaire, Ria (1994), "Repensando a História Literária”, Tendências e Impasses: o Feminismo como Crítica da Cultura, Ed. Heloísa Buarque de Hollanda, Rio de Janeiro, Rocco, 58-71.

Emerson Inácio é Professor Associado I da área de Estudos Comparados de Literaturas de Língua Portuguesa, no Departamento de Letras Clássicas e Vernáculas da Faculdade de Filosofia, Letras e Ciências Humanas da Universidade de São Paulo (USP), desde 2006; Livre Docente pela mesma IES (2016), com a tese Do corpo o canto, perfumada presença: o corpo, Fluxo-Floema e Novas Cartas Portuguesas, sendo Doutor em Letras Vernáculas pela UFRJ (2006). Concentra as suas abordagens sobre o Comparatismo Literário / Literatura Comparada, particularmente nos possíveis diálogos entre as Literaturas de Língua Portuguesa, com atenção às relações literárias e culturais entre Brasil e Portugal. 
Emerson Inácio

Entretanto, procura estar atento aos diálogos da Literatura com outros sistemas semióticos, em particular com a Música Popular Brasileira nas suas diversas manifestações, em particular com o Rap. Por acreditar que não há hierarquias entre as diversas manifestações da palavra escrita e falada, nem entre o centro e as margens, tem-se dedicado aos estudos sobre os cânones, as sexualidades, a teoria queer e as manifestações estéticas das afrodescendências. Tem várias publicações nas suas áreas de trabalho. 